NASA Technical Memorandum 105772

\title{
Energy Loss Analysis of an Integrated Space Power Distribution System
}

M. David Kankam

Lewis Research Center

Cleveland, Ohio

and

P.F. Ribeiro

Dordt College

Sioux Center, Iowa

Prepared for the

27th Intersociety Energy Conversion Engineering Conference cosponsored by the ANS, SAE, ASC, AIAA, IEEE, and AIChE San Diego, California, August 3-7, 1992

\section{N/SA}




\section{Energy Loss Analysis of An Integrated Space Power Distribution System}

\author{
M. David Kankam \\ National Aeronautics and Space Administration \\ Lewis Research Center \\ Cleveland, Ohio 44135
}

\author{
P.F. Ribeiro \\ Dordt College \\ Sioux Center, lowa 51250
}

\section{ABSTRACT}

This paper describes the results of studies related to conceptual topologies of an integrated utility-like space power system. The system topologies are comparatively analyzed by considering their transmission energy losses as functions of mainly distribution voltage level and load composition. The analysis is expedited by use of a Distribution System Analysis and Simulation (DSAS) software. This recently developed computer program by the Electric Power Research Institute (EPRI) uses improved load models to solve the power flow within the system. However, present shortcomings of the software with regard to space applications, and incompletely defined characteristics of a space power system make the results applicable to only the fundamental trends of energy losses of the topologies studied.

Accountability, such as included, for the effects of the various parameters on the system performance can constitute part of a planning tool for a space power distribution system.

\section{INTRODUCTION}

The major desired features of a space power distribution system include minimal mass and energy loss, high power quality and system reliability. Heat dissipation by radiation and the absence of atmosphere in space can cause high temperatures in the distribution system components. Hence, improved distribution system performance will require the management of any generated energy, heat dissipation, and power flow losses. This will keep the system operation within temperature constraints and, also, maximize power transfer within the system.

The objective of this paper is to determine the performance of some conceptual distribution system topologies of a space power system, with regard to the effect of distribution voltage level and load composition on the steady-state transmission line energy loss. The topologies studied are based on the layout of a conceptual Lunar base configuration in NASA's 90-day study (Refs. 1 and 2). Due to its functional diversity and characteristics, the Lunar base was used to provide the basic parameters for the analysis. The utility-based analysis approach and associated results contribute towards the planning of an integrated space power distribution system.

Calculation of the energy loss requires an accurate modelling of the distribution system load characteristics. This is achieved by using the Distribution System Analysis and Simulation (DSAS) program with built-in load energy models. The software was developed by the Electric Power Research Institute (EPRI) (Ref. 3). A discussion of the load modelling and energy analysis follows a brief description of a conceptual configuration of a space system. Subsequent sections discuss the various power system topologies studied, the prevailing assumptions, and some representative results.

\section{CONCEPTUAL SPACE POWER SYSTEM}

Figure 1 shows a conceptual Lunar base system configuration (Ref. 1). It shows the SP-100 thermoelectric and Stirling engine power generation stations. Relative distances between the stations and service centers are shown. Figure 2 is an equally conceptual power distribution and transmission system which can be representative of the network for Fig. 1. It is a utility-like distribution network for a nuclear power system. It illustrates an integration of the reactor power generation station with a conceptual space power system pertinent to NASA's Space Exploration Initiative program (Ref. 4). The figure shows the interconnections from the thermionic power plant to the load areas, namely, an oxygen production plant and the crew's habitat, via a network routed over transmission towers. 
The energy loss analysis described in this paper pertains to network topologies which are representative of simplified, single-line diagrams of a power distribution system such as shown in Fig. 2.

\section{ENERGY LOSS ANALYSIS AND LOAD MODELLING}

Minimization of ohmic losses in transmission lines is desirable for improved power transfer capability. The DSAS computer program is ideally suitable for calculating the energy consumption and losses of a distribution system. The program uses a three-phase load flow algorithm to simulate distribution systems with various load compositions and time periods, in a detailed manner (Refs. 3 and 5). Each transmission line is represented by its lumped-parameter, pi-equivalent model. A detailed modelling of power system equipment is not included in this mainly preliminary analysis for the enhancement of system planning.

There are many kinds of load components in a distribution system. Accurate determination of the power system load behavior requires a detailed model for each load component. Such load models and their loss terms are inherent in the DSAS. Furthermore, the DSAS uses information on the voltage, current, total power, ambient temperature, energy, and output capacity of the load components to derive corresponding load energy models. These models are then used to calculate the energy consumption at the load buses, based on the bus voltage and ambient conditions. Hence, a DSAS-derived load model is more representative of the actual load than the constant power load model used in a conventional load flow analysis.

\section{POWER SYSTEM TOPOLOGIES}

Four topologies (Ref. 6) are comparatively analyzed by their energy loss dependency on the distribution voltage level and load composition. They incorporate the necessary redundancy and reliability required in a power system.

Topologies 1 to 3 in Figs. 3 to 5, respectively, comprise solar and nuclear power generation sources, and connections to service and load centers. Each of the topologies has generation capacity of $550 \mathrm{MW}$. Topology 4 of Fig. 6 pertains to a Photovoltaic Regenerative Fuel Cell (PV/RFC) power source only. The total power of 75 $\mathrm{KW}$ can be viewed as sufficient for the operation of a basic scientific outpost.

Topology 1 is configured to supply the total power required, with sufficient level of redundancy and reliability. Multiple direct lines between the buses provide the redundancy for power flow to or from each bus. Increased reliability and redundancy are built into Topology 2 . An extra, intermediate bus is included to provide additional flexibility. Due to its increased number of transmission lines, Topology 2 is expected to be more massive than
Topology 1. Topology 3 is a variation of Topology 1 , where the mining facility is powered from the landing/ launching bus. With regard to power availability, Topology 1 provides better reliability to the mining bus.

In Figs. 3 to 5 , only one transmission line is schematically indicated between connected buses, for simplicity. In reality, each line represents four transmission lines, each of which is capable of carrying one third of the total load. Thus, the fourth line acts as a spare line to ensure the transmittal of the total required output power, in case of a line outage.

\section{BASIC ASSUMPTIONS}

The assumptions and operating conditions used in the study are summarized below. The numerical values are based on Refs. 1, 2 and 7 and typical values used in terrestrial utility systems:

1. The distribution system is centralized, $A C$ transmission of $60-\mathrm{Hz}$ frequency. This operating frequency is consistent with the specifications of the DSAS software.

2. The distribution voltage ranges from 1 to $10 \mathrm{kV}$.

\section{The transmission line is 1 to $5 \mathrm{~km}$ long.}

4. The connected load to each of Topologies 1,2 and 3 is either single-phase or three-phase, with a total load demand of $450 \mathrm{~kW}$. The load for Topology 4 is $75 \mathrm{~kW}$.

\section{DISCUSSION OF RESULTS}

All simulated cases correspond to the total transmission line energy losses (MWh), computed on the basis of a full lunar day or night (336 hr) (Ref. 7).

The results show that the transmission line energy losses can be significant, and are dependent on the system topology and voltage level, load composition, and power factor, among others.

Figure 7 depicts the variation of total transmission line loss with distribution line-line voltage. The results show, that for the assumed line lengths of 1 to $5 \mathrm{~km}$, and total connected load of $450 \mathrm{~kW}$, the energy loss is minimal for distribution voltage levels between 3 and $8 \mathrm{kV}$, for all the topologies studied. Thus, in the 3 to $8 \mathrm{kV}$ range, maximum power transfer to the load centers may be achievable. Topologies 1 to 3 , with similar configurations of varying reliability and redundancy, show similar energy loss profiles. Topology 4 displays a distinctively low energy loss which reflects its relatively low output power rating. Topologies 1 and 2 differ in configuration and, yet, exhibit similar energy lossdistribution voltage profiles. Compared to Topology 1 , the cumulative effect of the extra lines in Topology 2 is a reduction in the equivalent impedance of such current 
paths. This translates into an effectively reduced energy loss which offsets the otherwise increase in the combined energy loss of the individual lines in Topology 2. These counterbalancing effects may explain the similarity evidenced in the results of Topologies 1 and 2 .

Figure 8 of Topology 1 illustrates the effect of load type on the energy loss. Types 1 and 2 pertain to a set of typical, summer-time, three-phase industrial loads of identical, but different percentages of constituent composition. Similarly, load types 3 and 4 are the commercial counterparts for the winter period. In the absence of well-defined space loads, terrestrial load types 1 to 4 , summarized in Tables I and II, have been used for a varied representation of load options. The prevailing distribution voltage is $5 \mathrm{kV}$.

Examination of Tables I and II shows that load types 3 and 4 comprise a high percentage of high-energy consumption component, namely, a three-phase heat pump. Consistent with this observation, the results of Fig. 8 portray a 16 percent increase in energy loss between load types 1 and 4.

Figure 9 shows the effect of load power factor on the line energy loss for Topology 1 . The prevailing voltage is $5 \mathrm{kV}$. There is nearly 23 percent reduction in energy loss for power factor ranging from unity (resistive load) to 0.95 (inductive load). The decrease in energy loss is attributed to the transmission line capacitance compensation by the inductive load. The trends in Figs. 8 and 9 are representative of the other topologies studied. However, the level of energy loss varies among the topologies.

\section{CONCLUSIONS}

The objective of this paper is to determine the impact of distribution voltage and connected load composition on the transmission line energy loss of conceptual topologies for a space power distribution system. The study results show that the energy loss and, hence, power transfer capability of the system, depend on the above system and operating parameters. Such information, if obtained for detailed representations of candidate topologies, can be used as an input to the planning of a space power system.

Additionally to key factors such as the overall system mass, high temperature, radiation effects and high frequency, the distribution voltage, load power factor, and the mix of load composition should receive careful attention in the planning of any future space power system. This can be realized by incorporating the unique characteristics of a space power system in existing software packages for terrestrial power system analysis. Although energy loss is emphasized in this paper, the system robustness, namely, stability, reliability and redundancy, should be part of the planning process. Also, the selection of the most appropriate topology from competing space power distribution systems should be based upon analyses which incorporate the detailed models of the components within, and the anticipated operating conditions of, the power system.

\section{REFERENCES}

1. Power Systems Analysis for the 90-Day Study, NASA, 1989.

2. "Human Exploration of Space, A Review of NASA's 90Day Study and Alternatives," Committee on Human Exploration of Space, National Research Council, National Academy Press, Washington, D.C. 1990.

3. Distribution System Analysis and Simulation Program (DSAS), EPRI, 1985.

4. Mason, L.S., Schmitz, P.C., Gallup, D.R., "Lunar InCore Thermionic Nuclear Reactor Power System Conceptual Design," 8th Symposium on Space Nuclear Power Systems, Albuquerque, New Mexico, January 6-10, 1991.

5. "The Effects of Reduced Voltage on The Operation and Efficiency of Electric Systems," Vol. 1 - Field Tests and Computer Code Development, EPRI, 1984.

6. Ribeiro, P.F, "Lunar Base Power System Study; Energy Loss Analysis of an AC Distribution System," 1991 NASA/OAI Summer Research Fellowship Project Report, NASA Lewis Research Center, Cleveland, Ohio, August 1992.

7. "Electrical Transmission on the Lunar Surface, Part I DC Transmission," Space Power Institute, Auburn University, April 27, 1990.

\begin{tabular}{|c|c|c|}
\hline & \multicolumn{2}{|c|}{ Composition type } \\
\hline & $\begin{array}{c}1 \\
\text { Summer }\end{array}$ & $\begin{array}{c}2 \\
\text { Summer }\end{array}$ \\
\hline $\begin{array}{l}\text { 1. Three-phase central } \\
\text { air conditioner }\end{array}$ & 50 & 70 \\
\hline 2. Three-phase heat pump & 0 & 0 \\
\hline $\begin{array}{l}\text { 3. Small size } 3-\phi \text { motor } \\
\text { (variable torque) }\end{array}$ & 10 & 10 \\
\hline $\begin{array}{l}\text { 4. Small size } 3-\phi \text { motor } \\
\text { (constant torque) }\end{array}$ & 10 & 20 \\
\hline $\begin{array}{l}\text { 5. Medium size } 3-\phi \text { motor } \\
\text { (variable torque) }\end{array}$ & 10 & 0 \\
\hline $\begin{array}{l}\text { 6. Medium size } 3-\phi \text { motor } \\
\text { (constant torque) }\end{array}$ & 20 & 0 \\
\hline
\end{tabular}


Table II. - Three-Phase Load

Composition - Commercial

\begin{tabular}{|l|c|c|}
\hline & \multicolumn{2}{|c|}{ Composition type } \\
\cline { 2 - 3 } & $\begin{array}{c}3 \\
\text { Winter }\end{array}$ & $\begin{array}{c}4 \\
\text { Winter }\end{array}$ \\
\hline $\begin{array}{c}\text { 1. Three-phase central } \\
\text { air conditioner }\end{array}$ & 0 & 0 \\
$\begin{array}{c}\text { 2. Three-phase heat pump } \\
\text { 3. Small size 3- } \phi \text { motor } \\
\text { (variable torque) }\end{array}$ & 50 & 70 \\
$\begin{array}{c}\text { 4. Small size 3- } \phi \text { motor } \\
\text { (constant torque) }\end{array}$ & 10 & 10 \\
$\begin{array}{c}\text { 5. Medium size 3- } \phi \text { motor } \\
\text { (variable torque) }\end{array}$ & 10 & 20 \\
$\begin{array}{c}\text { 6. Medium size 3- } \phi \text { motor } \\
\text { (constant torque) }\end{array}$ & 15 & 0 \\
\hline
\end{tabular}

SP100/thermoelectric

generator

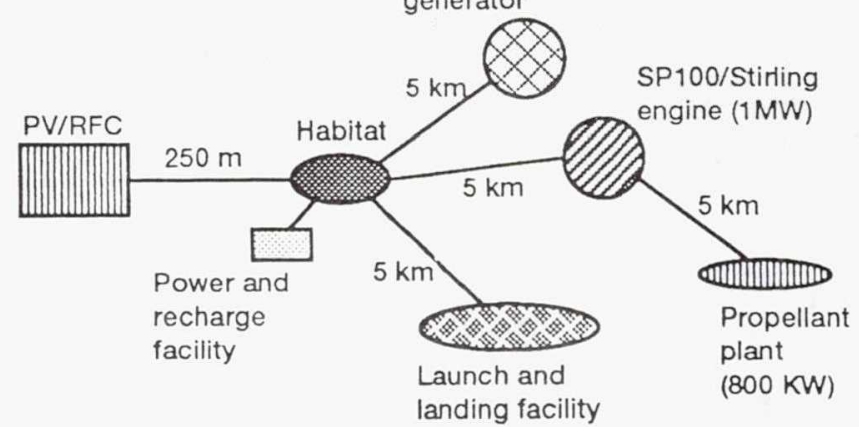

Figure 1.-Conceptual Lunar base system configuration.

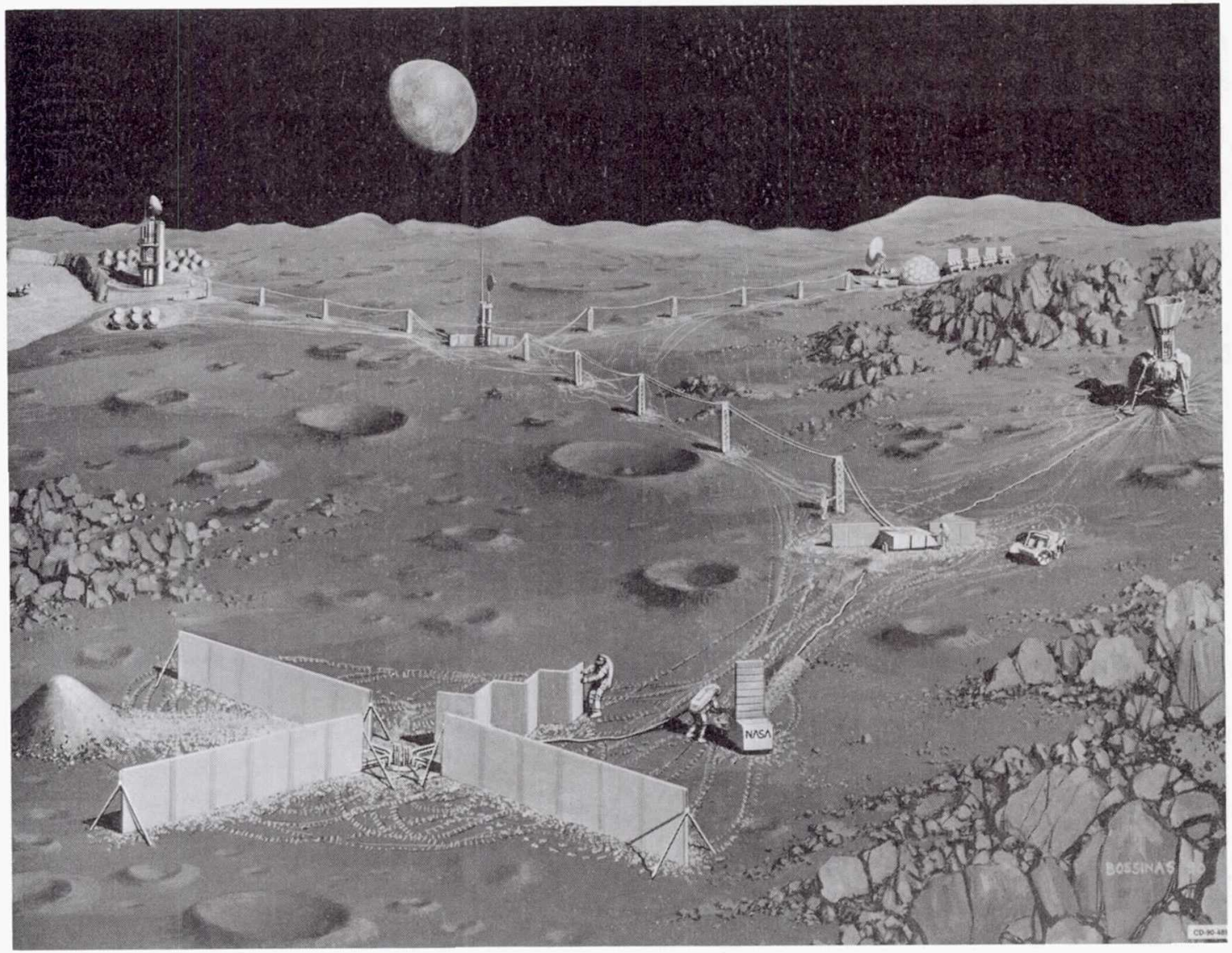

Figure 2.-Conceptual space power system. 


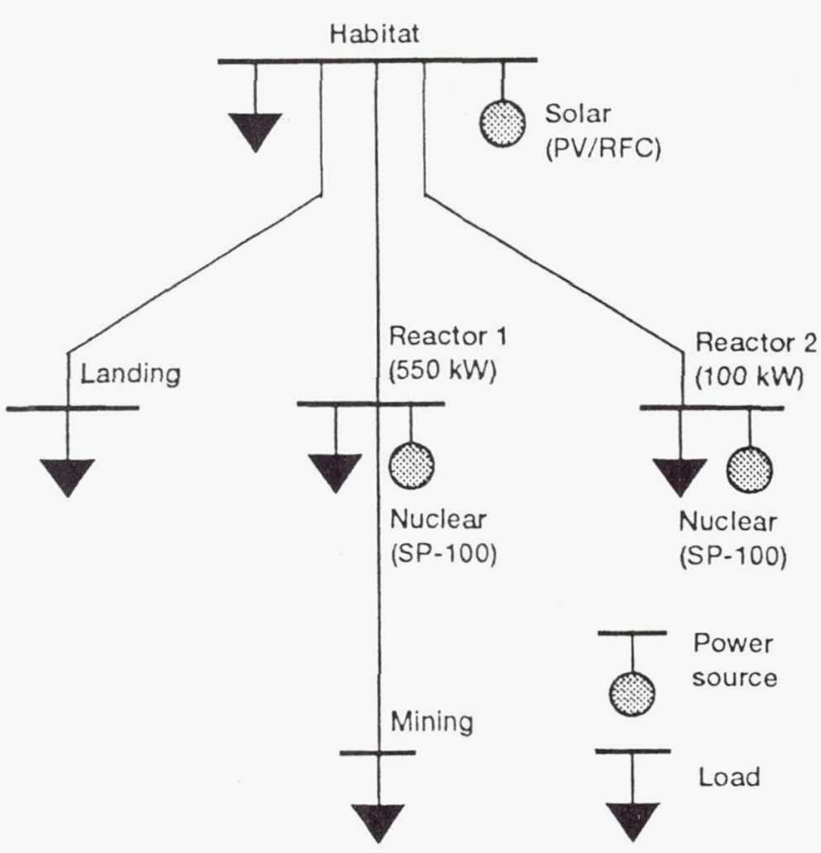

Figure 3.-Topology 1 with nuclear and solar power generation sources.

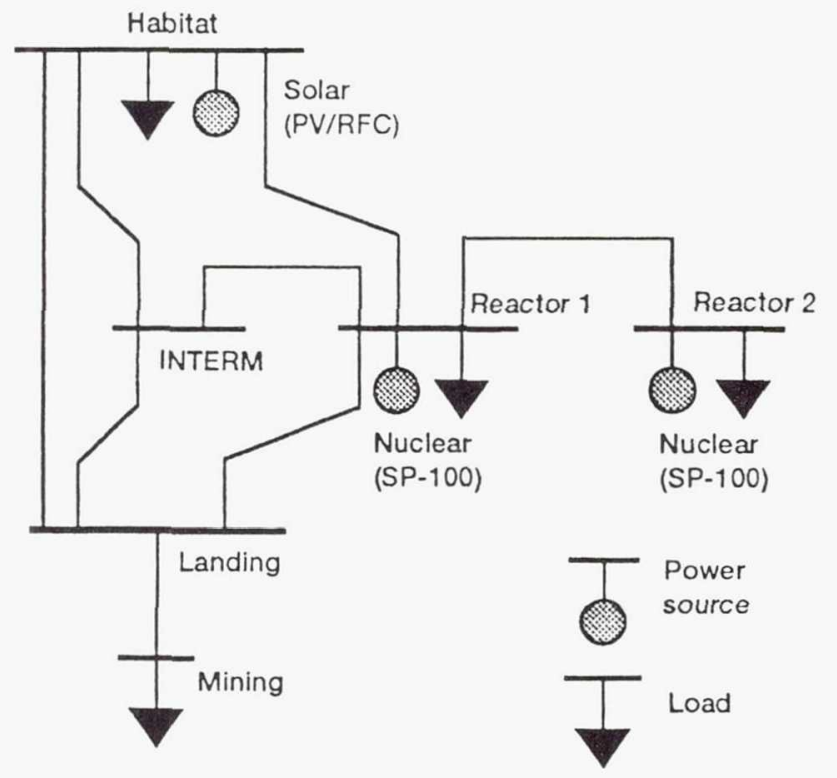

Figure 4.-Topology 2 with nuclear and solar power generation sources.

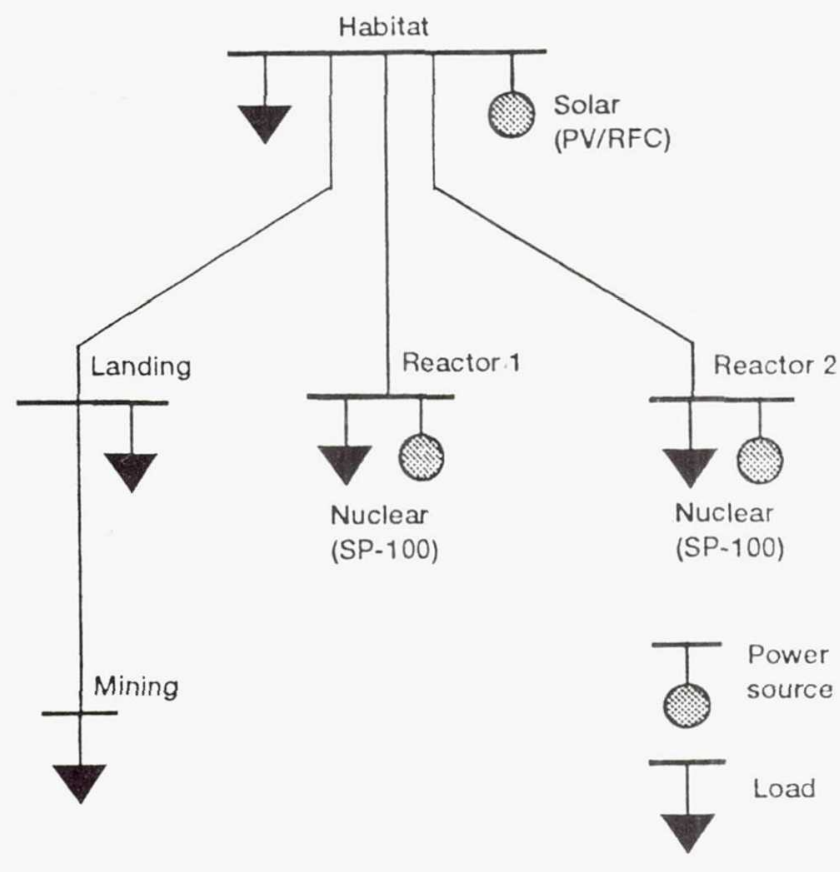

Figure 5.-Topology 3 with nuclear and solar power generation sources.

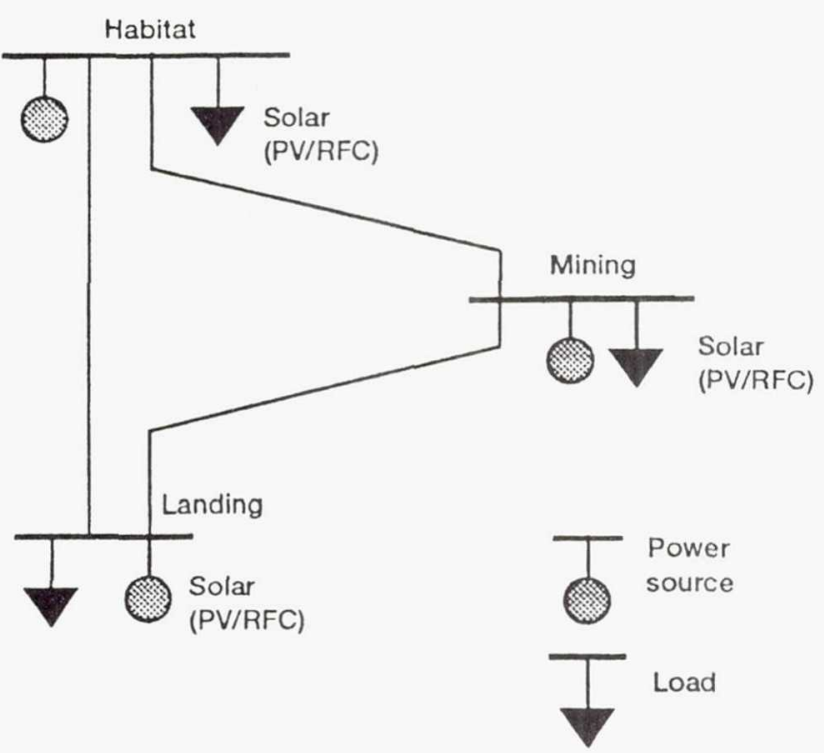

Figure 6.-Topology 4 with solar power generation sources. 


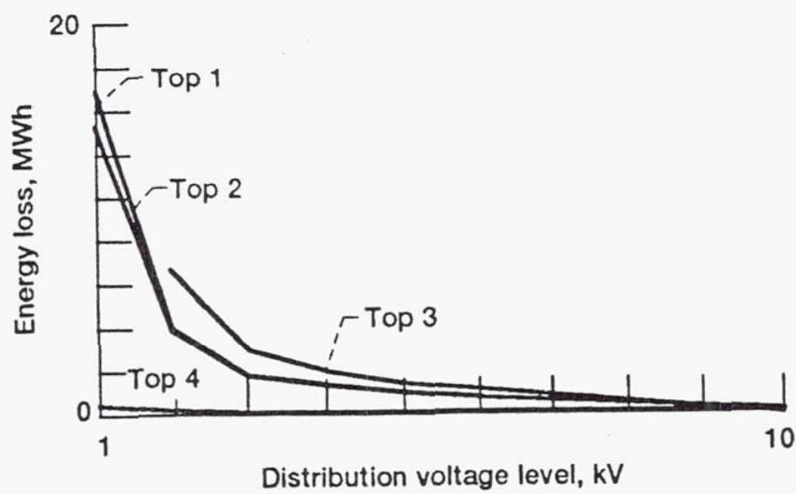

Figure 7.-Transmission line energy loss versus distribution voltage.
Load type

1. Summer, 36, industrial, composition 1

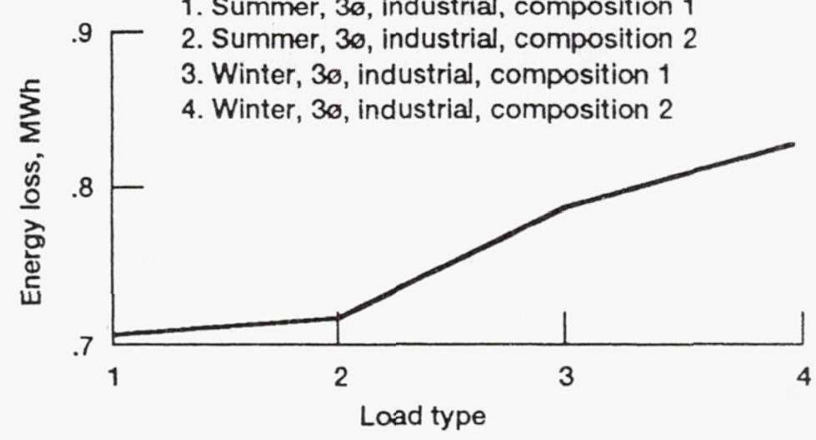

Figure 8.-Transmission line energy loss versus load composition for Topology 1 (distribution voltage, $5 \mathrm{kv}$ ).

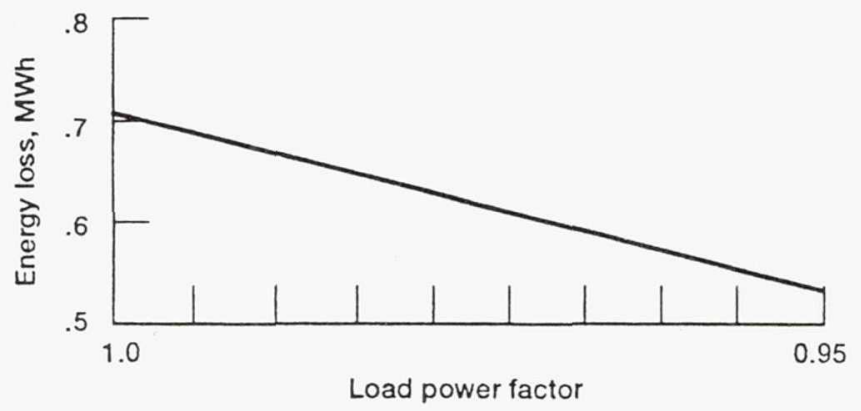

Figure 9.-Transmission line energy loss versus load power factor for Topology 1 (distribution voltage, $5 \mathrm{kv}$ ). 
Public reporting burden for this collection of information is estimated to average 1 hour per response, including the time for reviewing instructions, searching existing data sources, gathering and maintaining the data needed, and completing and reviewing the collection of information. Send comments regarding this burden estimate or any other aspect of this collection of information, including suggestions for reducing this burden, to Washington Headquarters Services, Directorate for information Operations and Reports, 1215 Jefferson Davis Highway, Suite 1204, Arlington, VA 22202-4302, and to the Office of Management and Budget, Paperwork Reduction Project (0704-0188), Washington, DC 20503.

\begin{tabular}{l|l} 
1. AGENCY USE ONLY (Leave blank) & 2. REPORT DATE
\end{tabular}

August 1992

3. REPORT TYPE AND DATES COVERED

4. TITLE AND SUBTITLE

Technical Memorandum

Energy Loss Analysis of an Integrated Space Power Distribution System

5. FUNDING NUMBERS

M. David Kankam and P.F. Ribeiro

WU-506-41-41

6. AUTHOR(S)

7. PERFORMING ORGANIZATION NAME(S) AND ADDRESS(ES)

8. PERFORMING ORGANIZATION REPORT NUMBER

National Aeronautics and Space Administration

Lewis Research Center

Cleveland, Ohio 44135-3191

E-7055

9. SPONSORING/MONITORING AGENCY NAMES(S) AND ADDRESS(ES)

10. SPONSORING/MONITORING

AGENCY REPORT NUMBER

National Aeronautics and Space Administration

Washington, D.C. 20546-0001

NASA TM-105772

11. SUPPLEMENTARY NOTES

Prepared for the 27th Intersociety Energy Conversion Engineering Conference, cosponsored by the ANS, SAE, ASC,

AIAA, IEEE, and AIChE, August 3-7, 1992. M. David Kankam, NASA Lewis Research Center, Cleveland, Ohio.

P.F. Ribeiro, Dordt College, Sioux Center, Iowa 51250. Responsible person, M. David Kankam, (216) $433-6143$.

12a. DISTRIBUTION/AVAILABILITY STATEMENT

Unclassified - Unlimited

Subject Category 28

13. ABSTRACT (Maximum 200 words)

This paper describes the results of studies related to conceptual topologies of an integrated utility-like space power system. The system topologies are comparatively analyzed by considering their transmission energy losses as functions of mainly distribution voltage level and load composition. The analysis is expedited by use of a Distribution System Analysis and Simulation (DSAS) software. This recently developed computer program by the Electric Power Research Institute (EPRI) uses improved load models to solve the power flow within the system. However, present shortcomings of the software with regard to space applications, and incompletely defined characteristics of a space power system make the results applicable to only the fundamental trends of energy losses of the topologies studied. Accountability, such as included, for the effects of the various parameters on the system performance can constitute part of a planning tool for a space power distribution system.

\section{SUBJECT TERMS}

Space power systems; Power system analysis and planning; Electric power flow; Transmission energy loss; Load modelling

\begin{tabular}{l} 
15. NUMBER OF PAGES \\
8 \\
16. PRICE CODE \\
$\mathrm{AO} 2$ \\
\hline 20. LIMITATION OF ABSTRACT
\end{tabular}

